\title{
Artikel
}

\section{Hoe betekenisvol is het participatierecht van het kind in de KNMG-meldcode kindermishandeling en huiselijk geweld (2018)?}

Mr. dr. M.P. Sombroek-van Doorm en D.M.A. Conway LLB*

\section{Inleiding}

Artikel 12 van het Internationaal Verdrag inzake de Rechten van het Kind (hierna: IVRK) bepaalt dat ieder kind vrijelijk zijn mening moet kunnen uiten in aangelegenheden die hem betreffen. ${ }^{1}$ Het recht van het kind om gehoord en serieus genomen te worden, vormt een van de fundamentele waarden van het IVRK. ${ }^{2}$ Het VN-Kinderrechtencomité benadrukt dat participatie van het kind van groot belang is in het kader van bescherming van kinderen tegen geweld en mishandeling. ${ }^{3}$ Wanneer een arts weet of vermoedt dat een kind mishandeld wordt, zal hij het kind op grond van het IVRK dus moeten betrekken bij de stappen die hij in dat kader zet. Daarbij is het uiteraard van belang dat de arts voortdurend rekening houdt met de veiligheid van het kind. De rol van de (huis)arts in geval van het signaleren en melden van kindermishandeling is in wettelijke,

* Mr. dr. M.P. Sombroek is universitair docent bij de afdeling Jeugdrecht van de Universiteit Leiden. D.M.A. Conway LLB is masterstudent Jeugdrecht aan de Universiteit Leiden.

1. Overal waar in deze bijdrage naar kinderen of artsen wordt verwezen met 'hij', 'hem' of 'zijn', kan tevens 'zij' of 'haar' gelezen worden.

2. General Comment No. 12 (2009), The right of the child to be heard, par. 2.

3. General Comment No. 13 (2011), The right of the child to freedom from all forms of violence, par. 63. Zie ook General Comment No. 12 (2009), par. 118-121. bestuurlijke en professionele regelgeving vastgelegd. De wetgever en de beroepsgroep van artsen redeneren dat (huis)artsen bij uitstek in de positie zijn om signalen van kindermishandeling te herkennen en aan te pakken. ${ }^{4}$ De Nederlandse overheid neemt maatregelen ter bestrijding van kindermishandeling onder meer in het kader van de internationale verplichting die op haar rust om kinderen tegen kindermishandeling te beschermen (art. 4 IVRK juncto art. 19 IVRK). ${ }^{5}$

Het gaat in Nederland naar schatting jaarlijks om tussen de 90.000 en 127.000 slachtoffers van kindermishandeling. ${ }^{6}$ In 2013 trad de Wet verplichte meldcode huiselijk geweld en kindermishandeling $(\mathrm{Wvm})$ in werking. ${ }^{7}$ Doel van deze wet is om kinderen tegen kindermishandeling te beschermen. ${ }^{8}$ De Wvm verplicht iedere beroepsgroep die met kinderen werkt om een meldcode huiselijk geweld en kindermishandeling op te stellen en het gebruik ervan te bevorderen. Deze verplichting is voor artsen inmiddels opgenomen in artikel 8 Wet kwaliteit klachten en geschillen zorg. In een meldcode wordt stapsgewijs aangegeven hoe met signalen van huiselijk

4. Kamerstukken II 2011/12, 33062, nr. 3, p. 9 (MvT); KNMG-Meldcode Kindermishandeling en huiselijk geweld, Utrecht: KNMG 2018, p. 19 (hierna: KNMG-meldcode 2018).

5. Maatregelen die in dit kader worden getroffen, moeten effectief zijn en de belangen van het kind vormen hierbij de eerste overweging (art. 19 IVRK juncto art. 3 IVRK).

6. L. Alink e.a., NPM-2017: Nationale prevalentiestudie mishandeling van kinderen en jeugdigen, Leiden: Universiteit Leiden/TNO 2018, p. 3-4 en 59-61.

7. Wet van 14 maart 2013 (Wet verplichte meldcode huiselijk geweld en kindermishandeling), Stb. 2013, 142

8. Kamerstukken // 2011/12, 33062, nr. 3, p. 4 (MvT). 
geweld en kindermishandeling moet worden omgegaan. Hoe die stappen eruitzien, staat beschreven in het Besluit verplichte meldcode (Bvm). ${ }^{9}$ In 2017 is hieraan de verplichting toegevoegd voor (onder andere) artsen om een 'afwegingskader' in de meldcodes op te nemen. ${ }^{10}$ Dat kader helpt artsen bij het maken van de afweging of zij wel of geen melding moeten doen aan Veilig Thuis, het advies- en meldpunt voor huiselijk geweld, kindermishandeling en ouderenmishandeling. De belangrijkste reden voor het verplicht stellen van zo'n afwegingskader is dat structurele situaties van kindermishandeling te weinig in beeld kwamen bij Veilig Thuis, waardoor zij onvoldoende konden worden tegengegaan. ${ }^{11}$ Daarnaast heeft de overheid in 2018 de Handreiking Participatie van kinderen in de meldcode huiselijk gemeld en kindermishandeling (hierna: Handreiking) in het leven geroepen. ${ }^{12}$ Door dergelijke maatregelen werkt de positieve verplichting die op de overheid rust om kinderen tegen kindermishandeling te beschermen, door in de horizontale relatie tussen arts, kind en ouders. In die Handreiking wijst de overheid er terecht op dat het betrekken van kinderen niet alleen belangrijk is voor het welzijn van het kind, maar ook voor de besluitvorming van de arts. ${ }^{13}$

Hoe artsen moeten handelen bij (vermoedens van) kindermishandeling is beschreven in de KNMG-meldcode kindermishandeling en huiselijk geweld 2018 (hierna: KNMG-meldcode). Daarin staan de stappen en het afwegingskader voor het doen van een melding van (een vermoeden van) kindermishandeling aan Veilig Thuis. ${ }^{14}$

In deze bijdrage staat de vraag centraal in hoeverre het participatierecht zoals neergelegd in artikel 12 IVRK in de KNMG-meldcode is ingebed. Daartoe wordt allereerst aandacht besteed aan de verschillende elementen van het participatierecht. Deze elementen beschrijven de stappen die volgens het VN-Kinderrechtencomité moeten worden genomen om betekenisvolle participatie van het kind te garanderen. ${ }^{15}$ Daarna wordt kort de KNMG-meldcode uiteengezet en ingezoomd op de stappen waarbij het kind betrokken wordt. Ten slotte volgt onderzoek naar de vraag in hoeverre het participatierecht van het kind tot zijn recht komt in de KNMG-

9. Besluit van 16 juli 2013 , houdende vaststelling van de minimumeisen voor de verplichte meldcode huiselijk geweld en kindermishandeling, Stb. 2013, 324

10. Besluit van 23 juni 2017, houdende wijziging van het Besluit verplichte meldcode huiselijk geweld en kindermishandeling, Stb. 2017, 291

11. Zie ook M.C. Ploem \& M.P. Sombroek, 'Afwegingskader voor melden van kindermishandeling: nog minder ruimte voor afwegen?', TVGR 2018 (42) 3, p. 221

12. Handreiking Participatie van kinderen in de meldcode huiselijk geweld en kindermishandeling, mei 2018 (hierna: Handreiking 2018)

13. Al eerder is kritiek geuit op de tot dan toe wat onderbelichte positie van kinderen, zie bijv. www.augeomagazine.nl/nl/magazine/11566/ 814193/protocollen_die_kinderen_negeren.html.

14. De geactualiseerde versie is vastgesteld op 15 november 2018 en trad officieel in werking op 1 januari 2019 (KNMG-meldcode 2018, p. 2).

15. General Comment No. 12 (2009), par. 40-47 en 113. Vgl. Handreiking 2018, p. 11-13 meldcode en in hoeverre hierbij kan worden gesproken over betekenisvolle participatie. ${ }^{16}$

\section{Participatierecht van het kind}

Het IVRK vraagt om een holistische lezing. ${ }^{17}$ Dit houdt in dat de verschillende kinderrechten, die betrekking hebben op vrijwel alle terreinen in het leven van kinderen, in samenhang moeten worden gezien en begrepen. Centraal in het verdrag staat het belang van het kind (art. 3 IVRK). Om te kunnen bepalen wat in het belang van het kind is, zal de arts het kind moeten betrekken in het proces waarin hij onderzoekt of het kind slachtoffer is van kindermishandeling en of hij daarvan een melding mag dan wel moet doen. Kennis van wat het kind denkt, voelt en wenst is immers cruciaal voor het inkleuren van het belang van het kind. Daarom heeft ieder kind ook het recht om te participeren in aangelegenheden die hem aangaan (art. 12 IVRK). ${ }^{18}$ In situaties van kindermishandeling is goed voorstelbaar dat participatie van het kind risico's met zich mee kan brengen voor de veiligheid van het kind thuis. In dat kader bepaalt het VNKinderrechtencomité dat volwassenen hierbij de verantwoordelijkheid hebben om voorzorgsmaatregelen te nemen die het risico op geweld minimaliseren. ${ }^{19}$

Maar wat houdt het recht om te participeren precies in? Het VN-Kinderrechtencomité legt in General Comment No. 12 uit dat het gaat om 'meaningful participation'. Betekenisvolle participatie is een proces van voortdurende wederzijdse informatie-uitwisseling tussen arts en kind; het hebben van slechts één gespreksmoment is onvoldoende. ${ }^{20} \mathrm{Om}$ betekenisvolle participatie te garanderen bij (vermoedens van) kindermishandeling moeten verschillende elementen terugkomen in de KNMGmeldcode: (i) informeren, (ii) aanmoedigen, (iii) afwegen, (iv) terugkoppelen en (v) mogelijkheid tot klacht of verzet. $^{21}$ Die verschillende elementen worden hierna nader toegelicht.

\section{Informeren}

Op grond van General Comment No. 12 zal de arts het kind allereerst moeten informeren over het recht om zonder geweld, mishandeling en verwaarlozing op te groeien, temeer nu kinderen die slachtoffer zijn van kin-

16. Vanwege de beperkte omvang van deze bijdrage spitst deze analyse zich toe op het onderdeel van de Meldcode dat ziet op het melden door de arts aan Veilig Thuis uit eigen beweging (preambule en art. 1-4 KNMG-meldcode 2018)

17. Zie bijv. General Comment No. 12 (2009) par. 2 en General Comment No. 13 (2011), par. 11 en 63. Zie ook General Comment No. 14 (2013) on the rights of the child to have his or her best interests taken as a primary consideration, par. 89.

18. Kinderen hebben daarin een keuze: zij mógen hun mening geven, het is geen verplichting (General Comment No. 12 (2009), par. 134 (b); zie ook Handreiking 2018, p. 19).

19. General Comment No. 12 (2009), par. 21 en 134 (h)

20. General Comment No. 12 (2009), par. 3 en 13. Zie ook Handreiking 2018 p. 13

21. General Comment No. 12 (2009), par. 40-47. Zie ook Handreiking 2018, p. 14-27 
dermishandeling hun opvoedingssituatie doorgaans als normaal beschouwen. ${ }^{22}$ In het licht van de bestrijding van kindermishandeling zou informatie over wat een normale omgang is tussen ouder en kind in een meldcode dus passend zijn. Dat vinden ook de opstellers van de Handreiking, die immers stellen dat informatie over wat als een normale gang van zaken geldt positieve effecten heeft op het herstel van het kind. ${ }^{23}$

Voorts moet het kind geïnformeerd worden over het recht dat hij heeft om zijn mening te geven en wat de betekenis van zijn mening zal zijn voor het verdere proces. In dit licht volstaat het niet om in algemene termen in een meldcode te vermelden dat de arts een gesprek zal voeren met 'betrokke(n)' of 'ouder en/of kind' of 'patiënt. ${ }^{24}$ Dit zijn té algemene bewoordingen en deze doen geen recht aan het participatierecht van het kind. Duidelijk moet bijvoorbeeld zijn op melke momenten de arts met het kind spreekt en vanaf melke leeftijd.

Onze wetgever hanteert in de Wet op de geneeskundige behandelingsovereenkomst ${ }^{25}$ leeftijdsgrenzen. Deze zijn kaderstellend voor het informeren van kinderen van wie de arts weet of vermoedt dat zij het slachtoffer zijn van kindermishandeling. ${ }^{26}$ Een kind dat 12 jaar of ouder is, moet bijvoorbeeld worden geinformeerd over het voorgenomen onderzoek, de voorgestelde behandeling en over zijn gezondheidstoestand. ${ }^{27}$ Jongere kinderen worden geinformeerd op een wijze die past bij hun bevattingsvermogen. ${ }^{28}$

In lijn met het IVRK moet het voor ieder kind transparant zijn wanneer, hoe, waar en met wie de communicatie plaatsvindt over (het vermoeden van) kindermishandeling en over de mogelijke beslissing dat er gemeld wordt aan Veilig Thuis. ${ }^{29}$ Participatie gaat immers om een proces van voortdurende wederzijdse informatieuitwisseling. De Handreiking benadrukt daarom dat in een meldcode duidelijk moet zijn door wie en wanneer het kind geïnformeerd wordt over de bestaande zorgen, welke stappen mogelijk worden gezet, wanneer en door wie het betrokken zal worden en wanneer en van wie het kind terugkoppeling krijgt. ${ }^{30}$

\section{Aanmoedigen}

Het betrekken van het kind betekent ook dat het kind moet worden aangemoedigd om zijn mening vrijelijk te

22. General Comment No. 12 (2009), par. 120

23. Handreiking 2018, p. 17-20.

24. Vgl. Handreiking 2018, p. 5

25. De Wet op de geneeskundige behandelingsovereenkomst (Wgbo) is neergelegd in Boek 7, Titel 7, Afdeling 5 BW, oftewel art. 7:446-468 BW.

26. Zie voor de relatie tussen het handelen bij kindermishandeling en de medische behandeling: M.P. Sombroek-van Doorm, Medisch beroepsgeheim en de zorgplicht van de arts bij kindermishandeling in de rechtsverhouding tussen arts, kind en ouders, Den Haag: Boom juridisch 2019, par. 8.3

27. Art. 7:448 lid $1 \mathrm{BW}$

28. Art. 7:448 lid $1 \mathrm{BW}$, laatste zin

29. General Comment No. 12 (2009), par. 25 en 41

30. Handreiking 2018, p. 14-20. uiten. ${ }^{31}$ De Handreiking stipuleert daarom dat de arts het kind naar zijn mening moet vragen, hem moet stimuleren deze te delen, bereid moet zijn hiernaar te luisteren en aan de mening van het kind passend gewicht moet toekennen in de beslissing die hij als arts maakt. ${ }^{32}$ Tegelijkertijd moet aan het kind duidelijk worden gemaakt dat het het recht heeft om te participeren, maar dat dit geen plicht is. ${ }^{33}$ Deze aspecten moeten dus terugkomen in de KNMG-meldcode, omdat zij inkleuring geven aan betekenisvolle participatie van het kind.

\section{Wegen van de mening}

De mening van het kind moet worden meegewogen in het licht van de te nemen beslissing over het al dan niet doen van melding van een vermoeden van kindermishandeling of over een gedane melding en de te bieden zorg aan het kind. Dergelijke beslissingen gaan het kind immers aan. Hoe de mening van het kind dient te worden meegewogen hangt af van het vermogen van het kind om een eigen mening te vormen. De arts moet dus kijken naar dit vermogen van het kind, zodat hij een passend gewicht kan toekennen aan de mening van het kind. ${ }^{34}$ Daarom zou in een meldcode ook moeten worden vastgelegd dat en hoe de mening van het kind wordt meegewogen in de besluitvorming. ${ }^{35}$

\section{Terugkoppelen}

Ten slotte zal de arts - als hij zijn beslissing heeft genomen over het al dan niet melden aan Veilig Thuis en ook na het doen van de eventuele melding - het kind hierover moeten informeren. Van belang daarbij is dat de arts aandacht besteedt aan de rol die de mening van het kind bij het nemen van die beslissing heeft gespeeld. ${ }^{36}$ Deze informatie-uitwisseling vormt een goede check of de mening van het kind inderdaad voldoende is meegewogen. ${ }^{37}$ Het kind voelt zich zo serieus genomen, zal de beslissing van de arts beter begrijpen dan zonder die uitleg en kan ook gerichter reageren op de beslissing van de arts. Het is dus van belang in een meldcode op te nemen dat en hoe het kind informatie krijgt over het uiteindelijke besluit, dat zijn visie op dat besluit gevraagd wordt en dat en hoe het kind informatie krijgt over hoe zijn visie is meegewogen in de besluitvorming. 38

\section{Mogelijkheid tot klacht of verzet}

Het participatierecht houdt ook in dat duidelijk moet zijn welke klachten- en herstelprocedures er gelden voor het kind als hij van mening is dat hij onvoldoende in de gelegenheid is gesteld om zijn mening te geven of dat zijn mening onvoldoende is meegewogen. ${ }^{39}$ Daarom zou in een meldcode moeten worden vastgelegd dat en hoe

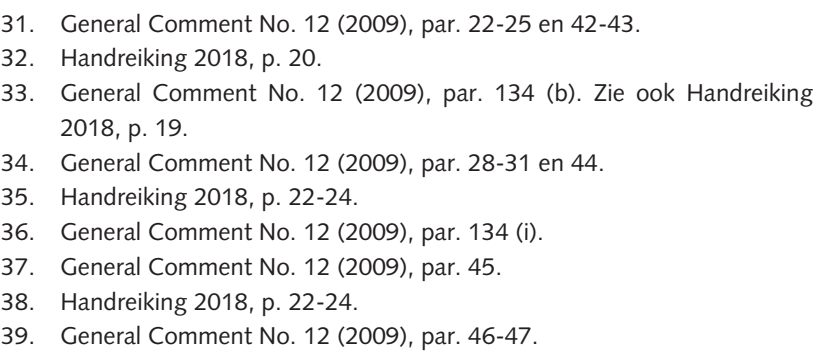


het kind kan klagen en hoe de klacht van het kind tegen de beslissing wordt meegewogen. ${ }^{40}$

\section{De KNMG-meldcode kindermishandeling en huiselijk geweld (2018)}

In de KNMG-meldcode huiselijk geweld en kindermishandeling (2018) staat beschreven dat de arts op grond van zijn wettelijke en professionele zorgplicht de verantwoordelijkheid heeft bij te dragen aan de bestrijding van kindermishandeling. In dit licht dient hij allereerst de signalen van kindermishandeling te verifiëren. ${ }^{41}$ Daartoe doorloopt de arts een stappenplan, zoals dat is neergelegd in artikel 4 van de KNMG-meldcode. De eerste vier stappen zijn specifiek gericht op de verificatie van een vermoeden van kindermishandeling.

Bij stap 1 (onderzoek) brengt de arts de signalen en aanwijzingen in kaart. Hij voert waar nodig een kindcheck uit. $^{42}$ Hij legt vervolgens de feiten en aanwijzingen vast in het medisch dossier. Voor zover de arts bij de verificatie van de signalen van kindermishandeling op grond van deze stap het kind onderzoekt, zal hij daarvoor toestemming nodig hebben volgens de regels van de Wet op de geneeskundige behandelingsovereenkomst. Deze regels houden in dat kinderen vanaf 12 jaar worden geïnformeerd over het onderzoek en het doel ervan en dat zij daarvoor ook hun toestemming moeten geven. ${ }^{43}$ Kinderen die de leeftijd van 12 jaar nog niet hebben bereikt, worden door de arts op zodanige wijze ingelicht als past bij hun bevattingsvermogen. De arts behoeft voor het te verrichten onderzoek evenwel geen toestemming van het kind, maar uiteraard wel van de ouders. ${ }^{44}$ Bij stap 2 vraagt de arts advies aan Veilig Thuis. Daarnaast vraagt hij ook advies aan een ter zake deskundige collega. De arts presenteert de casus anoniem en het kind wordt hierbij ook verder niet betrokken. Anders is dat volgens de KNMG-meldcode in stap 3. Bij die stap gaat het immers om het voeren van een gesprek met 'betrokkenen'. De opstellers van de KNMG-meldcode expliciteren dat de arts het vermoeden van kindermishandeling 'zoveel mogelijk bespreekt met het kind'. Dit kan al vanaf jonge leeftijd, voor zover het gesprek is aangepast aan het niveau van het kind, aldus de code. ${ }^{45}$ Ook kan de arts een signaal aan de Ver-

40. Handreiking 2018, p. 24.

41. Zie ook M.P. Sombroek-van Doorm, Medisch beroepsgeheim en de zorgplicht van de arts bij kindermishandeling in de rechtsverhouding tussen arts, kind en ouders, Den Haag: Boom juridisch 2019, par. 8.3.

42. Bij de kindcheck gaat de arts na of er in het gezin van zijn volwassen patiënt kinderen zijn die van deze patiënt afhankelijk zijn. Zo ja, dan gaat de arts na of de patiënt in staat is goed voor die kinderen te zorgen of, als dat niet zo is, in staat is daar hulp bij te vragen. Daarvoor checkt hij of de patiënt beschikt over een goed netwerk.

43. Art. 7:448 lid 1 BW juncto art. 7:450 lid 2 BW.

44. Art. 7:448 lid $1 \mathrm{BW}$. Met 'ouders' wordt in deze bijdrage verwezen naar de gezagdragende ouder(s) en/of voogd(en) van het kind.

45. Dit is in lijn met art. 7:448 lid 1 BW. wijsindex Risicojongeren (VIR) afgeven en/of met toestemming van de patiënt overleggen met andere betrokken professionals. ${ }^{46}$ Dit is stap 4 in het stappenplan. Opvallend is dat in de code vooral aandacht is voor het toestemmingsvereiste voor een dergelijk overleg of een dergelijke VIR-melding, maar niet is gepreciseerd in hoeverre de arts met het kind bespreekt wat hij gaat doen en waarom.

$\mathrm{Na}$ deze vier stappen die bedoeld zijn om het vermoeden van kindermishandeling te verifiëren, volgt stap 5 . Daarin worden, in de vorm van een afwegingskader, normen en criteria gegeven voor het bepalen of, in samenspraak met Veilig Thuis, de arts een melding doet of (nog) niet. Dat afwegingskader geldt sinds 1 januari 2019 en voorziet de arts van vijf afwegingsvragen die leiden tot de conclusie of een situatie of vermoeden van kindermishandeling en/of huiselijk geweld zo ernstig is dat een melding bij Veilig Thuis noodzakelijk is. Van noodzakelijkheid is sprake bij acute en/of structurele onveiligheid. Het afwegingskader bepaalt dat voor andere zorgwekkende situaties de arts in overleg met Veilig Thuis kan beoordelen of een melding bij Veilig Thuis toch ook noodzakelijk is. Daarnaast beschrijft het afwegingskader hoe de arts - na een melding - samen met Veilig Thuis kan vaststellen of hij effectieve hulp kan bieden en/of organiseren. ${ }^{47}$ De functie van het afwegingskader is dat beroepsbeoefenaren die met kinderen werken nog meer houvast hebben bij het omgaan met (een vermoeden van) kindermishandeling of huiselijk geweld door duidelijker te maken wanneer zich een meldingsplichtige situatie voordoet. ${ }^{48}$ De hulpverlening wordt niet langer aan Veilig Thuis overgedragen, ${ }^{49}$ maar in onderling overleg tussen arts en Veilig Thuis opgepakt. ${ }^{50}$

Steeds geldt dat de arts voordat hij een melding aan Veilig Thuis doet, in beginsel contact zoekt met het kind en/of zijn ouders. Bij kinderen jonger dan 12 jaar bepaalt de code dat de arts de melding bespreekt met ouders én beoordeelt of het - gelet op de aard van de melding, de relatie met het kind en diens leeftijd - 'ook mogelijk is om de stappen die hij zet en de informatie die hij verstrekt met het kind zelf te bespreken'. ${ }^{51} \mathrm{Bij}$ kinderen tussen de 12 en 15 jaar bespreekt de arts de melding met het kind en/of met ouders. De arts beoordeelt zelf of hij ouders en kind afzonderlijk spreekt of gezamenlijk. Is het kind 16 jaar of ouder, dan bespreekt de arts de melding met het kind zelf. Vindt de arts dat hij daarnaast ook met de ouders moet spreken, bijvoorbeeld als dat noodzakelijk is voor de veiligheid van het kind, dan overlegt hij dit met het kind, aldus de

46. Art. 7.1.4.1 Jeugdwet

47. KNMG-meldcode 2018, p. 27-36 (art. 4 stap 5).

48. KNMG-meldcode 2018, p. 27 (art. 4 stap 5). Zie ook M.C. Ploem \& M.P. Sombroek, 'Afwegingskader voor melden van kindermishandeling: nog minder ruimte voor afwegen?', TVGR 2018 (42) 3, p. 221.

49. Zie KNMG-meldcode 2018, p. 4 over deze aanpassing ten opzichte van de KNMG-meldcode van 2015

50. KNMG-meldcode 2018, p. 33-36 (art. 4 stap 5).

51. KNMG-meldcode 2018 , p. 28 (art. 4 stap 5). 
code. Is het kind wilsonbekwaam, dan bespreekt de arts de melding met de ouders. ${ }^{52}$

\section{De inbedding van het participatierecht in de KNMG- meldcode}

In hoeverre komen de hiervoor besproken elementen van het participatierecht ex artikel 12 IVRK terug in de KNMG-meldcode? Om te beginnen bepaalt de meldcode dat een arts alleen van een gesprek met het kind mag afzien indien dit risico's voor de veiligheid of gezondheid van de patiënt, de arts of anderen met zich mee zou brengen. De arts moet 'waar mogelijk' naar een ander geschikt moment zoeken om alsnog met het kind te spreken. ${ }^{53}$ De arts krijgt dus beperkte ruimte om participatie van het kind anders vorm te geven in het belang van het kind. De mogelijkheid die wordt opengelaten dat de arts helemaal niet spreekt met het kind is, hoewel in eerste opzicht niet in lijn met het participatierecht van het kind, toch begrijpelijk gezien de precaire thuissituatie bij kindermishandeling. ${ }^{54}$

\section{Informeren}

In de KNMG-meldcode staat niet vermeld dat de arts aan het kind moet uitleggen dat het kind het recht heeft om zonder geweld, kindermishandeling en verwaarlozing op te groeien en het recht heeft om zijn mening te geven. Dit zou in een gesprek met het kind over waarom de arts een onderzoek start naar signalen van kindermishandeling aan de orde kunnen komen. Voorts valt op dat de KNMG-meldcode té algemene bewoordingen gebruikt, zoals 'betrokkenen' en 'ouders en/of kind', die volgens de Handreiking onvoldoende recht doen aan het participatierecht van het kind. Anderzijds vermeldt de code wel in artikel 2 lid 3 dat de arts kinderen zoveel mogelijk procesinformatie moet geven, zodat zij weten wat er gaat gebeuren en waarom de arts besluit iets te doen. ${ }^{55}$ Dit kan, aldus de meldcode, al vanaf jonge leeftijd, mits het gesprek is aangepast op het niveau van het kind. Als het gaat om het doen van een melding aan Veilig Thuis, dan dient de arts aan de 'betrokkenen' uit te leggen dat hij een melding wil doen, wat dat betekent en wat het doel ervan is. ${ }^{56}$ Ofschoon de term 'betrokkenen' te algemeen is, is de uitleg over de betekenis en het doel

52. KNMG-meldcode 2018 , p. 28 (art. 4 stap 5).

53. KNMG-meldcode 2018 , p. 25 (art. 4 stap 3) en p. 29 (art. 4 stap 5)

Het VN-Kinderrechtencomité geeft aan dat bij de vormgeving van participatie van het kind de volledige bescherming van het kind verzekerd moet worden (General Comment No. 12 (2009), par. 21). Volwassenen moeten voorzorgsmaatregelen nemen wanneer participatie van het kind het risico oplevert voor de veiligheid van het kind (General Comment No. 12 (2009), par. 134 (h)). Auteurs vinden het begrijpelijk dat de arts, in uitzonderlijke situaties waarin risico's voor het kind niet op andere manieren afgewend kunnen worden, de ruimte krijgt om het kind nog niet of zelfs helemaal niet te betrekken bij de stappen die hij onderneemt.

55. KNMG-meldcode 2018, p. 18 (art. 2).

56. KNMG-meldcode 2018 , p. 28 (art. 4 stap 5).

van de melding in lijn met de inkleuring die aan het participatierecht wordt gegeven. De code geeft de arts ruimte om ook het kind jonger dan 12 jaar te betrekken bij de melding zelf, maar hoe de arts dat precies moet doen, blijft ongewis. ${ }^{57}$

\section{Aanmoedigen}

De KNMG-meldcode geeft weliswaar een antal aanwijzingen in bijlage 6 met gesprekstips voor het informeren van het kind, maar het verdere verloop van het gesprek blijft onderbelicht. Op grond van de code moet de arts, nadat hij uitlegt dat hij een melding wil doen, daarop een reactie vragen aan de patiënt en/of diens ouders. De enige toelichting hierop in de code is dat de arts zich 'dus' moet inspannen om toestemming te krijgen. ${ }^{58}$ De gespreksvoering moet in het kader van kindermishandeling echter op veel meer zien, zoals de bestaande zorgen die er zijn, wat de arts vanuit zijn rol en verantwoordelijkheid kan betekenen voor het kind en ook wat hij juist niet kan. ${ }^{59}$ Daarnaast is het belangrijk dat kinderen te horen krijgen dat wat zij meemaken reden kan zijn voor een interventie. ${ }^{60}$ Naast inhoudelijke informatie over de besluiten die de arts van plan is te nemen, is het belangrijk dat kinderen informatie krijgen over de manier waarop besluiten tot stand komen, op welke manier zij daarin kunnen participeren en dat de verantwoordelijkheid voor de te nemen beslissingen en vervolgacties niet bij het kind ligt, maar bij de arts. ${ }^{61} \mathrm{De}$ code zou hierover duidelijker kunnen zijn en vermelden dat bepaalde onderwerpen aan de orde moeten komen in het gesprek met een kind. De gesprekstips uit bijlage 6 van de KNMG-meldcode zijn weliswaar waardevol voor aanmoediging van een vrije meningsuiting en sluiten aan bij wat de Handreiking voorstelt, maar meer dan aanwijzingen zijn het niet. ${ }^{62}$

Voorts vermeldt de KNMG-meldcode dat signalen van kindermishandeling al vanaf jonge leeftijd met kinderen kunnen worden besproken, mits het gesprek is aangepast aan het niveau van het kind. ${ }^{63}$ De gesprekstips geven de arts hier in ieder geval handvatten voor. ${ }^{64}$

De KNMG-meldcode legt nergens vast dat de arts aan het kind moet uitleggen dat het aan het kind zelf is om te bepalen of hij betrokken wil worden bij de beslissingen die de arts zal nemen. Dit is een gemis, nu voor het het gebeurd? Waar heb je pijn? Wie heeft dat gedaan?', 'Wissel deze af met gesloten vragen: Ben je gevallen? Heb je pijn? Ging je huilen? Vond je dat leuk of niet leuk?', 'Vraag het kind wat het zelf wil'. Voor jongeren: 'Benoem concreet wat u bij de jongere waarneemt of heeft gezien, en vraag hem om daar iets meer over te vertellen', 'Luister naar de reactie van de jongere', 'Vraag de jongere wat hij zelf wil'. KNMGmeldcode 2018, p. 54-55 (Bijlage 6).

63. KNMG-meldcode 2018 , p. 25 (art. 4 stap 3).

64. KNMG-meldcode 2018, p. 54-55 (Bijlage 6). 
kind duidelijk moet zijn dat zijn participatierecht geen plicht is. ${ }^{65}$

\section{Wegen van de mening}

De arts zal moeten afwegen of hij nog steeds een vermoeden heeft van (dreigende) kindermishandeling. Logischerwijs wegen de gesprekken met kind en/of ouders hierin mee. De bereidheid van 'betrokkenen uit het (gezins)systeem ${ }^{66}$ om effectieve hulp te accepteren weegt tevens mee in het afwegingskader. ${ }^{67}$ De KNMGmeldcode verplicht de arts evenwel niet om de mening van het kind mee te wegen en ook wordt niet duidelijk gemaakt hoe de mening van het kind moet worden meegewogen in de besluitvorming. ${ }^{68}$

\section{Terugkoppelen}

De KNMG-meldcode expliciteert niet dat een kind een terugkoppeling móet krijgen over het uiteindelijke besluit en dat zijn visie daarop gevraagd moet worden. Duidelijk wordt dat dat afhankelijk is van de leeftijd en de wilsbekwaamheid van het kind. In het licht van het participatierecht ex artikel 12 IVRK is dit wellicht voor de groep kinderen jonger dan 12 jaar op zijn minst wat vrijblijvend geformuleerd. ${ }^{69}$

\section{Mogelijkheid tot klacht of verzet}

De KNMG-meldcode legt ook niet vast dat en bij wie het kind bezwaar kan maken als hij vindt dat hij onvoldoende gelegenheid heeft gekregen om zijn mening te geven of dat deze mening onvoldoende is meegewogen. Zonder (kennis van) deze mogelijkheden kan het participatierecht van het kind niet effectief gewaarborgd worden. ${ }^{70}$

\section{Conclusie}

Betekenisvolle participatie is cruciaal om ervoor te zorgen dat de arts in het belang van het kind kan handelen wanneer hij weet of vermoedt dat het kind mishandeld wordt. Uiteraard geldt dat als de veiligheid van het kind door te participeren in gevaar komt, de arts in het belang van het kind moet handelen. De KNMG-meldcode voorziet hierin door te bepalen dat de arts bij risico's voor de veiligheid of gezondheid van het kind (of anderen) (nog) geen informatie verstrekt aan het kind of stappen (nog) niet bespreekt met het kind. De opstellers van de KNMG-meldcode hebben nadrukkelijk vastgelegd dat de arts (buiten bovengenoemde uitzonderingssituatie) het kind moet betrekken bij zijn handelen in geval van (vermoedens van) kindermishandeling. Dit valt te waarderen, maar er is nog zeker ruimte voor ver- betering. Uit bovenstaande analyse blijkt immers dat niet alle elementen voor een betekenisvolle participatie in de KNMG-meldcode terugkomen. Zo is het niet duidelijk dat en door wie het kind geinformeerd wordt over zijn recht om zonder geweld op te groeien en zijn mening te geven. Voorts komt niet helder naar voren hoe het kind in het besluitvormingsproces betrokken zal worden, hoe zijn mening zal meewegen en hoe het kind tegen besluitvorming bezwaar kan maken. Ook zou duidelijker gemaakt moeten worden welke onderwerpen in het gesprek tussen arts en kind ten minste aan bod moeten komen en welke vragen de arts moet stellen. De KNMG-meldcode besteedt verder te weinig aandacht aan de wijze waarop de mening van het kind in de besluitvorming wordt meegewogen, zowel tijdens het proces als nadat een melding aan Veilig Thuis is gedaan. Daartoe zou de KNMG-meldcode beter kunnen uitwerken hoe de vermogens van het kind (in het bijzonder het kind onder de 12) om een eigen mening te vormen beoordeeld moeten worden. Voorts staat niet in de KNMG-meldcode vermeld dat en hoe het kind bezwaar kan maken. Kortom, de KNMG-meldcode besteedt weliswaar aandacht aan de participatie van kinderen, maar het is nog te vroeg om te kunnen spreken van een betekenisvolle participatie van kinderen zoals bedoeld in artikel 12 IVRK, terwijl dat nu juist in het belang is van de kinderen om wie het hier gaat.
66. Ook hier zou de meldcode concreter kunnen aangeven of het om kind, kind en ouders of ouders gaat (vgl. Handreiking 2018, p. 5).

67. KNMG-meldcode 2018, p. 33-36 (art. 4 stap 5 afweging 3, 4 en 5).

68. General Comment No. 12 (2009), par. 45.

69. General Comment No. 12 (2009), par. 45 en 134 (i).

70. General Comment No. 12 (2009), par. 46-47. 